\title{
Arthroscopic Treatment of Multidirectional Glenohumeral Instability in Young Overhead Athletes
}

\author{
C. Voigt ${ }^{*}, 1,2$, A.P. Schulz ${ }^{2}$ and H. Lill ${ }^{1}$ \\ ${ }^{1}$ Department of Trauma and Reconstructive Surgery, Friederikenstift Hospital Hannover, Humboldtstrasse 5, D-30169 \\ Hannover, Germany \\ ${ }^{2}$ Department of Orthopaedics and Trauma, University Hospital Schleswig Holstein, Campus Lübeck, Ratzeburger Allee \\ 160, D-23538 Lübeck, Germany
}

\begin{abstract}
Purpose: This prospective case series evaluates the outcome, and the return to sports of young overhead athletes with a persistent, symptomatic multidirectional instability (MDI) with hyperlaxity type Gerber B5 treated with an arthroscopic anteroposteroinferior capsular plication and rotator interval closure.

Methods: 9 young overhead athletes (10 shoulders) with the rare diagnosis of MDI (Gerber B5) and an indication for operative treatment, after a failed physiotherapy program were physically examined 3, 6 and 12 months postoperatively by a physical examination, and got a final phone interview after median 39 months.

Results: At the final follow-up all patients were satisfied; Rowe Score showed 7 "excellent" and "good" results; Constant Score was "excellent" and "good" in 6, and "fair" in 1 patient. 7/9 returned to their previous sports, 3/9 at a reduced level.

Conclusion: Symptomatic MDI requires an individual indication for surgical treatment after a primary conservative treatment. The described arthroscopic technique stabilizes glenohumeral joint. A return to overhead sports is possible but often at a reduced level; returning to high-performance sports cannot be recommended because of the high risk of reinstability.
\end{abstract}

Keywords: Shoulder, multidirectional instability, athletes, arthroscopy, capsular shift.

\section{INTRODUCTION}

The true multidirectional shoulder instability (MDI) with hyperlaxity classified as a Gerber B5-instability is a very rare entity $(<5 \%)$ of shoulder instabilities [1] but it increases in an increasing number of young, overhead athletes [2,3]. MDI force them to quit sports, and compromises their everyday life [4]. Therefore, MDI gets more important, and its treatment is still a challenge.

Current literature about MDI is infrequent [4-11], and often not clear in definition and differentiation of MDI. The true MDI is defined as a symptomatic instability in more than two directions [12], and has to be differentiated exactly from the unidirectional instability with hyperlaxity (Gerber B3; $30 \%$ of shoulder instabilities), or the physiological hyperlaxity [1].

The aetiology of MDI is unclear; repetitive microtrauma, proprioceptive imbalances of the dynamic glenohumeral stabilizers and congenital, anatomical abnormalities of the glenoid are discussed [4].

Conservative treatment is the preferred initial therapy, and successful in the most patients $[4,6,7]$. A specific exercise program [13] is recommended for at least 3 months before considering any surgery $[6,7]$. Indication for surgery

*Address correspondence to this author at the Friederikenstift Hospital Hannover, Humboldtstrasse 5, D-30169 Hannover, Germany; Tel: +49-511129-2331; Fax: +49-511-129-2405; E-mail: christine.voigt@ddh-gruppe.de arises from persistent shoulder pain and slipping, including avoidance of activities [4]. Literature shows that up to $37 \%$ of MDI-patients need a surgical treatment [7, 9, 14]. The purpose of this prospective study was to evaluate the functional outcome, and the return to sports in young overhead athletes with a persistent, symptomatic MDI (Gerber B5) treated with an arthroscopic anteroposteroinferior capsular plication and interval closure. The hypothesis, that the described arthroscopic technique stabilizes glenohumeral joint, and enables overhead athletes to return to their previous sportive level was under investigation.

\section{MATERIAL AND METHODOLOGY}

\section{Patients}

After institutional review board approval, in a trauma and shoulder center over a period of 2 years, 9 ( 7 female, 2 male) consecutive young overhead athletes (10 shoulders) were included in this prospective case control study. Inclusion criteria were young $(<30$ years) overhead athletes with a symptomatic MDI with hyperlaxity (Gerber B5) that persisted after a controlled exercise program (minimum 3 months). All patients gave their informed consent prior to their inclusion. Catchment area of patients was $>400 \mathrm{~km}$, which emphasizes the rare occurence of this entity. The mean age was 18 years (range, 13-28 years) at the time of surgery. Bilateral symptoms existed in 5 patients. The dominant side was involved in 6 patients. All were predominantly active in high-level overhead sports. 
Table 1. Patient Demographics

\begin{tabular}{|c|c|c|c|c|c|c|c|c|c|c|c|c|}
\hline \multirow[b]{2}{*}{ No. } & \multirow[b]{2}{*}{$\begin{array}{l}\text { Age } \\
{[y]}\end{array}$} & \multirow[b]{2}{*}{ Gender } & \multirow[b]{2}{*}{ Sports } & \multicolumn{4}{|c|}{ Hyperlaxity Signs } & \multicolumn{2}{|c|}{ Instability Signs } & \multirow{2}{*}{$\begin{array}{c}\text { Gerber } \\
\text { Classification } \\
{[1]}\end{array}$} & \multirow{2}{*}{$\begin{array}{c}\text { Prior } \\
\text { Direction } \\
\text { of } \\
\text { Instability }\end{array}$} & \multirow{2}{*}{$\begin{array}{c}\text { Preoperative } \\
\text { Physiotherapy } \\
\text { [mo] }\end{array}$} \\
\hline & & & & $\begin{array}{c}\text { Anterior } \\
\text { Translation } \\
{[15]}\end{array}$ & $\begin{array}{c}\text { Posterior } \\
\text { Translation } \\
{[15]}\end{array}$ & $\begin{array}{l}\text { Sulcus } \\
\text { Sign } \\
{[16]}\end{array}$ & $\begin{array}{c}\text { Gagey } \\
\text { Sign }\end{array}$ & Apprehension & $\begin{array}{l}\text { Yerk } \\
\text { Sign }\end{array}$ & & & \\
\hline 1 & 13 & $\mathrm{f}$ & tennis* & $\mathrm{II}^{\circ}$ & $\mathrm{II}^{\circ}$ & $\mathrm{II}^{\circ}$ & + & + & + & B5 & anterior & 4 \\
\hline 2 & 23 & $\mathrm{f}$ & volleyball* & $\mathrm{II}^{\circ}$ & $\mathrm{II}^{\circ}$ & $\mathrm{II}^{\circ}$ & + & + & + & B5 & posterior & 12 \\
\hline 3 & 28 & $\mathrm{f}$ & handball* & $\mathrm{II}^{\circ}$ & $\mathrm{I}^{\circ}$ & $\mathrm{I}^{\circ}$ & + & + & - & B5 & anterior & 36 \\
\hline 4 & 17 & $\mathrm{~m}$ & water polo* & $\mathrm{II}^{\circ}$ & $\mathrm{II}^{\circ}$ & $\mathrm{III}^{\circ}$ & + & + & + & B5 & anterior & 6 \\
\hline 5 & 17 & $\mathrm{f}$ & swimming & $\mathrm{II}^{\circ}$ & $\mathrm{II}^{\circ}$ & $\mathrm{III}^{\circ}$ & + & + & + & B5 & posterior & 3 \\
\hline 6 & 14 & $\mathrm{f}$ & volleyball & $\mathrm{I}^{\circ}$ & $\mathrm{II}^{\circ}$ & $\mathrm{II}^{\circ}$ & + & - & + & B5 & posterior & 13 \\
\hline 7 & 16 & $\mathrm{f}$ & volleyball & $I^{\circ}$ & $\mathrm{II}^{\circ}$ & $\mathrm{II}^{\circ}$ & + & - & + & B5 & posterior & 3 \\
\hline 8 & 15 & $\mathrm{~m}$ & volleyball* & $\mathrm{II}^{\circ}$ & $\mathrm{I}^{\circ}$ & $\mathrm{II}^{\circ}$ & + & + & + & B5 & anterior & 3 \\
\hline 9 & 16 & $\mathrm{f}$ & volleyball & $\mathrm{II}^{\circ}$ & $\mathrm{II}^{\circ}$ & $\mathrm{II}^{\circ}$ & + & + & + & B5 & posterior & 12 \\
\hline 10 & 20 & $\mathrm{f}$ & swimming & $\mathrm{II}^{\circ}$ & $\mathrm{II}^{\circ}$ & $\mathrm{II}^{\circ}$ & + & + & + & B5 & posterior & 6 \\
\hline
\end{tabular}

*Major league; f: female, m: male. Case 5 and 10 are the left and the right shoulder of the same patient.

Inclusion criteria were young $(<30$ years) overhead athletes with a symptomatic MDI (Gerber B5) that persisted after a controlled exercise program (minimum 3 months). Individuals with asympto-matic hyperlaxity, unidirectional instability with hyperlaxity (Gerber B3) [1], traumatic onset, bony injuries (Hill-Sachs-, Bankart-lesions), previous shoulder surgery, or psycho-logical abnormalities were excluded.

\section{Clinical and Radiological Evaluation}

Diagnosis was made on 1) Patient's history with painful sensations of looseness and slipping, or dislocation, and 2) Physical examination that demonstrated hyperlaxity by an excessively anterior, posterior and inferior translation classified by Hawkins and Bokor [15], and the sulcus sign, that was performed by applying an inferior force on the hanging arm in neutrally, internally and externally rotated arm positions. A persistent inferior translation in external rotation indicated an insufficiency of the rotator interval, in internal rotation a laxity of the posterior capsule. Sulcus sign was quantified by the distance between the lateral acromial border and the humeral head, and classified by Altcheck et al. [16] (Table 1). All patients demonstrated positive signs of hyperlaxity: Gagey sign, Sulcus sign, as well as an increased anterior and posterior translation (Table 1).

Instability was diagnosed with positive apprehensionand/or Jerk-tests. In 6 cases the predominant direction of instability was posterior, in 4 anterior (Table 1). Three patients had had documented posterior dislocations, 2 others anterior dislocations. Senior author confirmed the diagnosis of a true MDI (Gerber B5) in all patients.

After first diagnosis of MDI, all patients received a controlled exercise program according to Burkhead and Rockwood [13] with strengthening, and balancing of rotator cuff muscles and scapular stabilizers for a median of 6 months (range, 3-36 months) to improve the coordination and muscular control of the glenohumeral joint, and to compensate instability. Persistent symptoms indicated surgical stabilization by an arthroscopic anteroposteroinferior capsular shift and rotator interval closure.

Preoperatively, all patients got a radiographic evaluation (true a.p. and axillary view) to rule out bony injuries like Hill-Sachs-lesions or Bankart-fractures, as signs a posttraumatic instability without hyperlaxity. As well as, a preoperative Magnetic Resonance Imaging (MRI) was performed that showed concomitant Superior Labral tear from Anterior to Posterior (SLAP) $\mathrm{II}^{\circ}$-lesion (Table 1, Case $2)$, as well as labrum atrophies anteroinferior $(n=2)$, posteroinferior $(n=2)$ and both $(n=1)$.

\section{Surgical Technique and Intraoperative Evaluation}

Under anaesthesia detailed examination of the degree and directions of the instability was performed in side-to-side comparison by the surgeon to affirm the diagnosis. Senior author did all operations. General surgical intention was to reconstruct the appropriate tension of the capsule and the inferior glenohumeral ligament complex.

In general anaesthesia first patients were placed in a lateral position with a gentle lateral arm-traction $(3 \mathrm{~kg})$ in $30^{\circ}$ of abduction, which eased the access to the axillary pouch and posterior capsule. Thereafter, posterior portal was placed, using "outside-in" technique for the arthroscope. It should be positioned approximately $1 \mathrm{~cm}$ more laterally than usual to afford for a better access to the posteroinferior capsule. During the diagnostic view, the "drive through sign", an easy slipping of the arthroscope through the joint space between glenoid and humeral head, was characteristic for a wide capsular volume. The state of labrum and glenohumeral ligaments were assessed. Additional portals anterior, superior to the subscapularis tendon, and anterosuperior, lateral to the biceps tendon were created. In the anterosuperior portal arthroscope was placed during capsular shift; the anterior and posterior portals were used for instrument passage, capsular plication, suture management and knot tying. Cannulas were inserted to avoid soft tissue wrapping. Before plication capsule was needled to promote healing. 
Capsular laxity responsible for the predominant direction of instability was addressed at first. The arm was in neutral rotation during capsular shifting. If predominant direction was posterior, capsular shift began at 5 (left side) or 7 o'clock position (right side) (Fig. 1).

In case of a well-developed labrum capsular plication was realized by sutures, which were passed through labrum and capsular tissue. If labrum was atrophic, suture anchors (Suture tak, Fa Arthrex, Naples, USA) were inserted to the glenoid rim to perform capsular shift. By a shuttle relay $\left(90^{\circ}\right.$ curved lasso), or alternatively an angled instrument with a sharp tip capsule tissue was grasped, and perforated about 1 to $1.5 \mathrm{~cm}$ lateral to the glenoid rim, nonabsorbable sutures (Fiber wire 2, Fa Arthrex, Naples, USA) were passed through the tissue in an O-shaped fashion, and posteroinferior capsular plication was performed (Fig. 2).

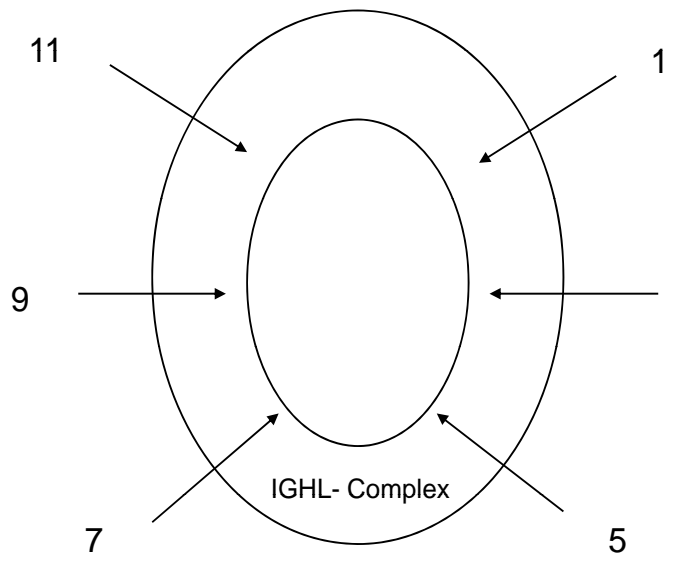

Fig. (1). Schematic diagram of the anteroposteroinferior capsular shift. Sutures in 1, 3, 5, 7, 9 and 11 o'clock position. IGHLcomplex - Inferior Glenohumeral Ligament-complex.

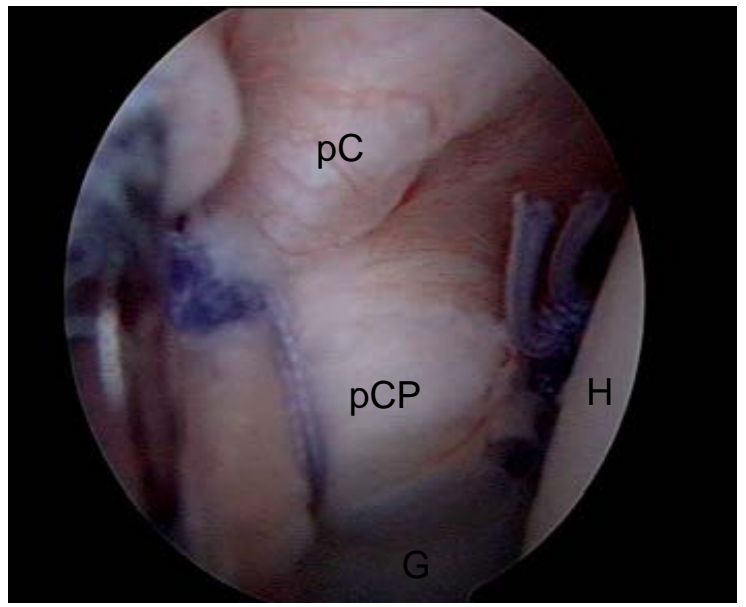

Fig. (2). Posteroinferior capsular shift (16 years, female). Left shoulder, lateral position; view from anterosuperior. H: Humerus, G: Glenoid, pC: posterior Capsule, pCP: posterior Capsular Plication.

Therefore, lasso could be inserted percutaneously in the optimal angle for capsular shifting. IGHL-complex was included in the shifted tissue. A sliding, locking knot was used to fold the capsule over itself. Same procedure was repeated at 3 (left side) or 9 o'clock (right side), and if necessary at 1 (left side) or 11 o'clock (right side), as well as anterior, respectively (Fig. 3).

Inferior capsular shift had to be performed in an inferiorsuperior direction to reduce axillary pouch (Fig. 1). Capsular plication acts as a kind of neolabrum, reduces intraarticular volume, increases tension, and decreases joint instability. Each stabilization was completed by a rotator interval closure (Fig. 4).

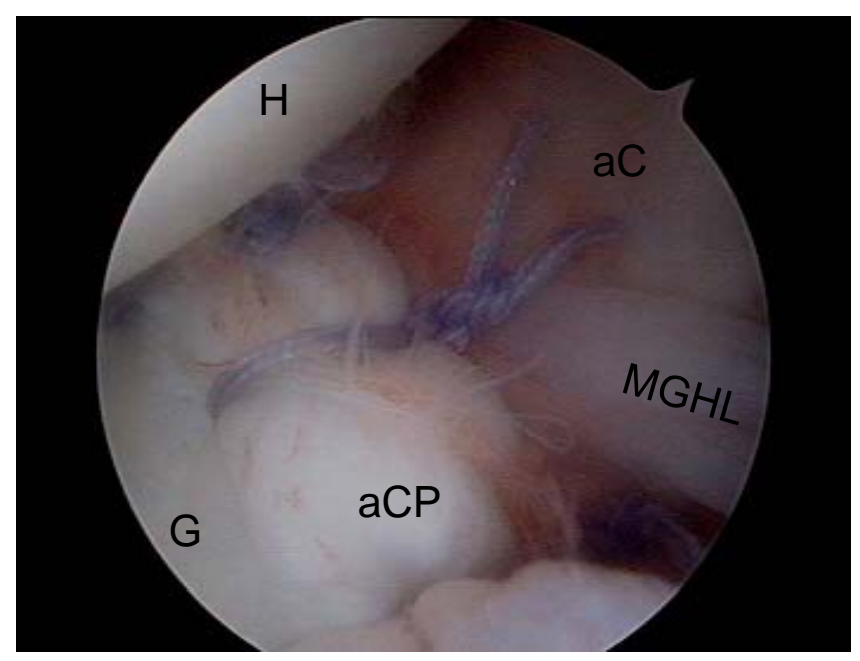

Fig. (3). Anteroinferior capsular shift (16 years, female). Left shoulder, lateral position; view from anterosuperior. H: Humerus, G: Glenoid, aC: anterior Capsule, aCP: anterior Capsular Plication, MGHL: Medial Glenohumeral Ligament.

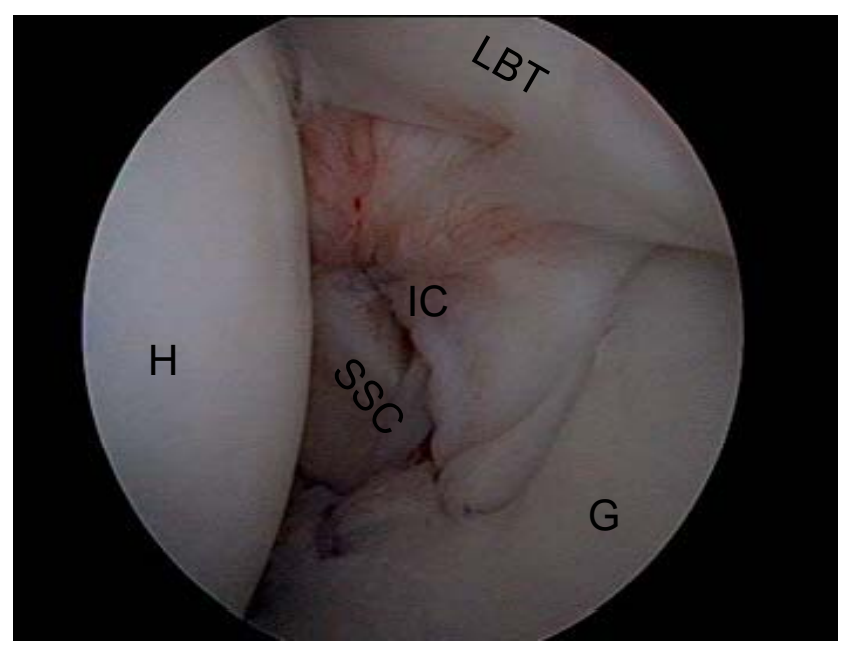

Fig. (4). Interval closure (16 years, female). Left shoulder, lateral position; view from dorsal. H: Humerus, G: Glenoid, IC: Interval Closure, LBT: Long Bicipital Tendon, SSC: M. subscapularis.

Therefore, arthroscope was inserted posteriorly. Patients arm was positioned in $20-30^{\circ}$ external rotation. Anterior cannula was slightly retracted out of the capsular level. Two sutures were passed close to the border of superior and middle glenohumeral ligament (SGHL, MGHL), and tied extraarticulary [4]. 


\section{Postoperative Rehabilitation}

Postoperative rehabilitation after arthroscopic multidirectional stabilization started with an immobilization at a $15^{\circ}$-shoulder-abduction-orthosis for 6 weeks; isometric exercises began immediately. In the $7^{\text {th }}$ and $8^{\text {th }}$ week active abduction and anterior flexion $\leq 90^{\circ}$ without any rotation was allowed. After 8 weeks an increasing free active range of motion and a strengthening under physiotherapeutic supervision were performed. Three months postoperatively full range of motion should be achieved, and the return to sports began. Contact sports were allowed 6 months after surgery.

\section{Follow-Up Evaluation}

In this case series 8 patients and 9 shoulders (90\%) completed the comprehensive follow-up. One female patient was not available because of an unknown new address. Patients were evaluated 3, 6 and 12 months after surgery by a personal interview, and a physical examination by the first author. All patients received a final phone interview median 39 months (range, 9-45 months) after surgery.

At all follow-up examinations Simple Shoulder Test (SST) [17] and Constant Murley Score (CMS) [18] as common, global shoulder scores were evaluated to compare results to the majority of previous reports. Furthermore, the instabilityspecific Rowe Score [19] with the main criteria: pain, stability, function, range of motion, and strength was assessed. A Visual Analog Scale was used for self-assessment of shoulder pain in the scores. Instability was diagnosed by the Apprehension- and Jerk-Tests, and graded as normal, if no discomfort, signs of subluxations, or muscular contractions were demonstrated. Ranges of motion of both shoulders were measured by a goniometer in all three planes. Isometric strength was assessed in comparison to the collateral side.

\section{Statistical Analysis}

Data were reported as mean $( \pm \mathrm{SD})$; range (minimummaximum), and analyzed by means of descriptive statistics with use of SPSS (Version 14.0, Chicago, USA). All statistical tests were applied two-sidly and non-parametrically, because analysis of the data did not show a normal distribution. The Wilcoxon test was performed to compare the related samples. P-values $\leq 0,05$ were considered statistically significant.

\section{RESULTS}

\section{Operative Findings}

All patients capsule showed a capacious capsular volume and a positive "drive-through sign", which was characteristic of patients with MDI. These findings were based on observations and experience of the senior author. Anteroinferior labrum atrophy was present in two patients, posteroinferior labrum atrophy in two other patients, and both in one patient; five shoulders had a labrum without any pathology. We saw one SLAP I - (Table 1, case 8), and one SLAP II - lesion (Table 1, Case 2), intraoperatively. SLAP II - lesion was stabilized with two suture anchors. There was a Buford Complex in one case (Table 1, Case 1); SGHL, MGHL and Inferior Glenohumeral Ligament (IGHL) were normal, otherwise. Rotator cuff tears, Bankart- or HillSachs-Lesions were not observed.

\section{Follow-Up Examinations}

\section{Satisfaction}

$4 / 8$ patients were very satisfied with their results (Table 1, Cases 3, 4, 8, 10). 3/8 were satisfied but complained of mild shoulder pain in overhead sports $>1 \mathrm{~h}$ (Table $\mathbf{1}$, Cases 2, 7).

3/8 patients (double mention) sustained a symptomatic reinstability and required reoperation (Table $\mathbf{1}$, Cases $\mathbf{1}, \mathbf{5}$, 9). To date, they are satisfied, but their expectations were not fulfilled in two cases.

\section{Scores}

Simple Shoulder Test (SST) and Constant Murley Score (CMS) showed a significant decrease 3 months postoperatively due to a reduced shoulder strength, and no significant improvement in the final follow-up (Table 2); final CMS was "excellent" in 3 patients, "good" in 3 cases and "fair" in 1 patient. Two other patients, 2 and 5 months after reoperation, could not be examined to the final point of this study (Table 1, Cases 1, 9*). Rowe Score continuously increased 3, 6, 12 months postoperatively, and did not change significantly from the 12 months to the final followup $(\mathrm{p}=0.180)$ (Table 2). Final Rowe Score showed 5 "excellent" and 2 "good" results (without*). Fig. (5) demonstrates the postoperative changes of the Rowe Score parameters (Fig. 5).

Shoulder stability increased immediately 3 months after surgery $(p=0.010)$; pain was significantly reduced $(\mathrm{p}=0.039)$. ROM was unrestricted in 7 of 9 patients. No patient lost more than $5^{\circ}$ external rotation (median $0^{\circ}$, range $0^{\circ}$ to $5^{\circ}$ ), finally.

Between 3 and 12 months postoperatively Activities of Daily Living (ADL) improved non-significantly $(\mathrm{p}=0.053)$. Preoperative levels of strength were reached at 12 months follow up $(\mathrm{p}=0.157)$. The slightly increasing stability from the 12 months to the final follow-up was non-significant $(\mathrm{p}=1.000)$, and due to the reoperations (Table $\mathbf{1}$, Cases $\mathbf{1}, \mathbf{5}$, 9) median 14 months (range, 14-40 months) postoperatively (Fig. 5).

\section{Return to Sports}

$3 / 8$ athletes (4/9 shoulders) returned to their previous sportive level $(\mathrm{n}=1$ major league, $\mathrm{n}=2$ minor league, $\mathrm{n}=1$ club level; Tegner activity level scale: level $9 n=1$, level 8 $n=1$, level $7 n=1$, level $5 n=1$ ) median 10 months (range, 9-12 months) after surgery (Table $\mathbf{1}$, Cases $\mathbf{3}, \mathbf{4}, \mathbf{8}, \mathbf{1 0}$ ). In 3 other cases the return to sports was estimated at $80 \%$ of the previous levels (minor league $\mathrm{n}=1$, club level $\mathrm{n}=2$; Tegner activity level scale: level $7 n=1$, level $5 n=1$, level $4 n=1$ ). Patients complained about shoulder pain in long-lasting $(>1$ h) overhead activities (Table 1, Cases 2, 5, 7). The major league tennis player (Table $\mathbf{1}$, Case 1) returned to highperformance training 6 months postoperatively, suffered pain, and finally experienced a reinstability 32 months after surgery. One other patient (Table 1, Case 9), who sustained a reinstability because of incompliance in the early postoperative time interval, is still in the rehabilitation program. 


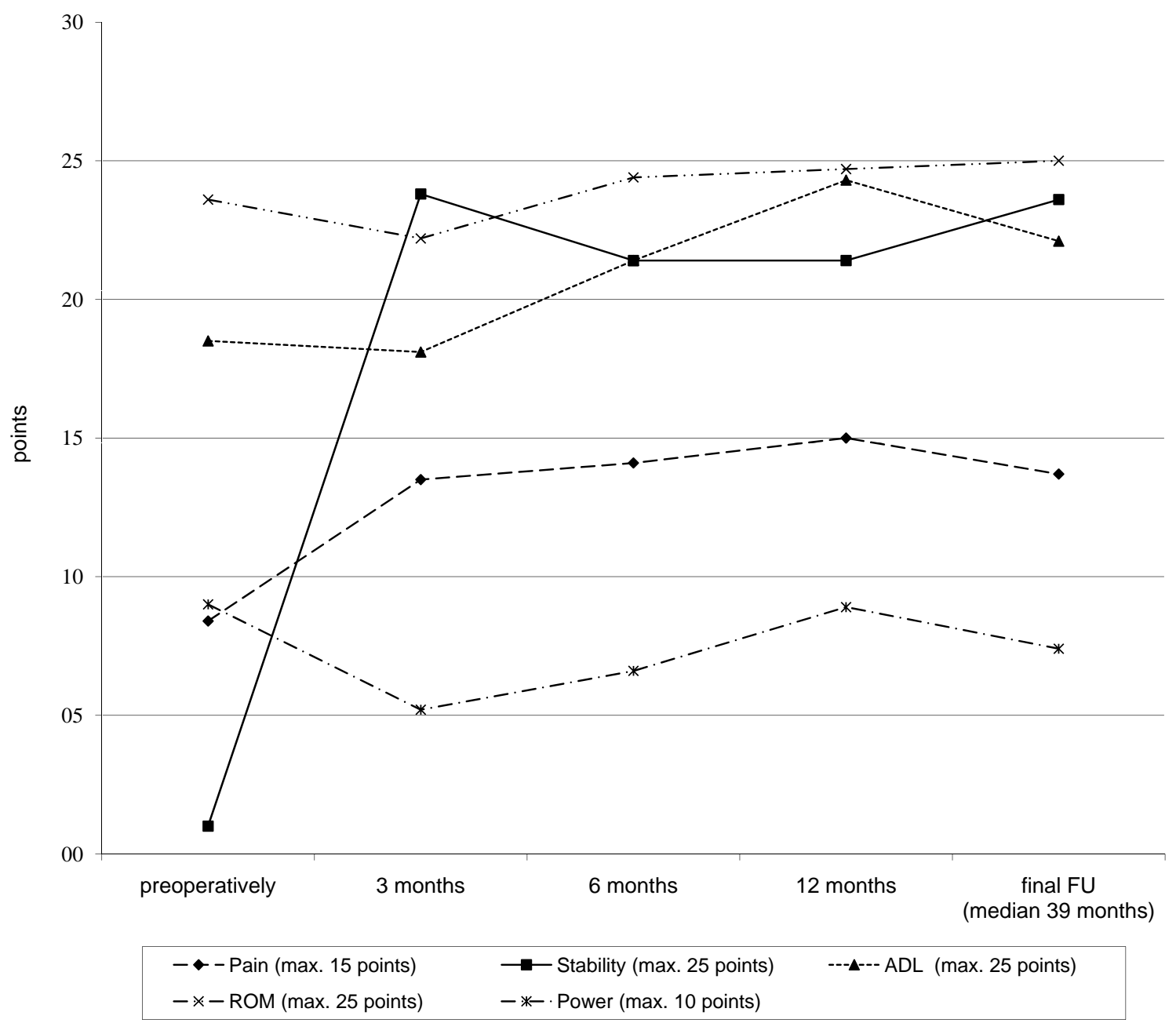

Fig. (5). Changes in the Rowe score parameters. ADL: Activities of Daily Living, ROM: Range of Motion, Max: maximum.

\section{Complications}

Reoperation was indicated in 3 of 9 patients with reinstabilities (Table 1, Case 1, 5, 9). One of these patients restarted the high-level training in tennis 6 months postoperatively against medical advice (Table $\mathbf{1}$, Case $\mathbf{1}$ ); the second patient was incompliant in the early exercises (Table 1, Case 9). In both cases posterior capsule sutures teared out 32 and 6 months postoperatively, and an open dorsal capsular shift according to Neer [12] was necessary 40 and 14 months after primary surgery, respectively. Third patient with a small glenoid received a dorsal bone block transfer according to Maurer and Resch [20] combined with a dorsal capsular shift (Table 1, Case 5) 14 months after primary surgery.

Complications regarding suture anchors were not seen. Vascular or neurological complications, wound healing problems, or infections were not observed.

\section{DISCUSSION}

The described arthroscopic technique and a high compliance in the postoperative rehabilitation program were found to stabilize the shoulder joint of MDI patients efficiently for everyday activities. The majority (7/9 cases) of our series returned to their sports after surgery, but the previous sportive level in overhead activities was achieved in only $4 / 8$ patients (4/9 shoulders). Our hypothesis, that in cases of a persistent, symptomatic MDI with hyperlaxity, the described arthroscopic technique stabilizes glenohumeral joint could be confirmed, but has to be restricted in its second part, to enable overhead athletes to return to their previous sportive level.

Current literature described the technique of arthroscopic anteroposteroinferior capsular shift with interval closure as an adequate technique to stabilize MDI of the glenohumeral joint as well $[10,21]$. Reported results after arthroscopic surgery are comparable to those achieved by open techniques $[5,10,21]$.

Clinical results varied from previous cadaveric studies. Cohen et al. [22] compared 3-suture arthroscopic plication $(5,3-4$, and 7-8 o'clock) with an open humeral-based Tcapsular shift described by Neer and Forster [12], and found open procedure superior with a joint volume reduction of $50 \%$ versus $23 \%$. Whereas currently, arthroscopic multipleated capsular plication described by Sekiya et al. [23] achieves a capsular volume reduction at least as well as with the open technique.

Important predictors of outcome and preconditions of good results are an accurate patient selection, the correct 
Table 2. Summary of Statistical Analysis of the Differences Between the Preoperative Scores and the Various Assessment Intervals

\begin{tabular}{|c|c|c|c|c|c|c|}
\hline Assessment Interval & $\begin{array}{c}\text { SST } \\
\text { Mean } \pm \text { SD }\end{array}$ & P-Values & $\begin{array}{c}\text { CMS } \\
\text { Mean } \pm \text { SD }\end{array}$ & P-Values & $\begin{array}{l}\text { Rowe Score } \\
\text { Mean } \pm \text { SD }\end{array}$ & P-Values \\
\hline Preoperative & $10.9 \pm 2.2$ & & $87.2 \pm 14.9$ & & $60.5 \pm 12.9$ & \\
\hline 3 months & $9.6 \pm 1.7$ & $\mathrm{P}=0.015^{*}$ & $80.4 \pm 7.1$ & $0.017 *$ & $81.7 \pm 9.4$ & $0.018^{*}$ \\
\hline 6 months & $10.9 \pm 2.5$ & $\mathrm{P}=0.317$ & $92.0 \pm 3.4$ & 0.609 & $88.0 \pm 10.6$ & $0.018^{*}$ \\
\hline 12 months & $11.0 \pm 2.6$ & $\mathrm{P}=0.317$ & $98.3 \pm 3.0$ & $0.016^{*}$ & $94.3 \pm 12.7$ & $0.017 *$ \\
\hline Final follow up median 39 months (range; 9 to 45 ) & $11.0 \pm 1.2$ & $\mathrm{P}=0.655$ & $91.0 \pm 10.2$ & 0.865 & $91.8 \pm 8.3$ & $0.018^{*}$ \\
\hline
\end{tabular}

SST: Simple Shoulder Test, CMS: Constant Murley Score, SD: Standard Deviation. *p < 0,05; significant.

diagnosis, and addressing the whole complex pathoanatomy of the shoulder instability [10]. The aim is to restore the appropriate tension of the capsule and the glenohumeral ligament complex without over- tightening the shoulder [6] and to augment a congenitally deficient or insufficient labrum [4]. The exact amount of volume reduction required to eliminate instability is still undefined [22]. Quantifying the correct amount of capsular shift is a challenge, and is based on sufficient experience in arthroscopic shoulder surgery. Excessive tensioning will reproduce the same concerns as over constrained open surgical stabilization [11].

Capsular plication under arthroscopic visualisation allows a controlled and precise balancing of the anterior and posterior capsuloligamentous tissue by varying location, magnitude, and number of sutures. This may be advantageous to an an open procedure additive to the wellknown advantages of arthroscopic surgery, including avoiding damage of the subscapularis tendon $[4,6]$. The described technique is addressed to two aspects of MDI: to reduce the capacious capsular volume, and to augment the congenitally deficient or insufficient labrum [4]. Rotator interval has been shown to have a significant role in glenohumeral instability [24-26]. An additive interval closure has been observed to be beneficial, especially in anterior instabilities [4, 24, 25, 27, 28, 30].

An alternatively described arthroscopic treatment of shoulder instabilities is thermal capsulorhaphy $[6,9]$. Whereas, it was very popular initially, reported results were contentious. Frohstick et al. [9] described encouraging early results after arthroscopic capsular shrinkage in patients with MDI; however failure rate was 16\%. D`Alessandro et al. [29] reviewed 53 shoulders with MDI treated with isolated capsular shrinkage at 38 months of follow-up. $42 \%$ of these had an unsatisfactory outcome, 19\% required restabilization at mean 19 months after initial surgery [29]. Currently, isolated thermo shrinkage of capsule tissue is not recommended [6].

Our study showed a significant improvement in the instability-specific Rowe score from 3 to 6 months postoperatively, and trended to a plateau with mean "good" and "excellent" results. The main reason for the improved score was the achieved stability. Pain improvement seemed to be followed by ADL and strength [9]. SST and CMS temporarily decreased within 3 months after stabilization mainly due to a reduced strength. External rotation was not impaired significantly $\left(<5^{\circ}\right)$ as seen in other clinical $(2-8$, $\left.5^{\circ}\right)[4,8,21]$, and biomechanical studies $[24,25]$. From one year to the final follow-up no significant deterioration was observed.

A controlled rehabilitation program was essential for a good result by protecting the healing capsular tissue, and avoiding the negative effects of immobilization $[6,10]$. In one case of incompliance during the early postoperative interval leads to a failure of the posterior sutures with reinstability. Another reinstability occurred 32 months after initial stabilization. It was caused by an early return to highlevel tennis 6 months after stabilization against medical advice. Incompliance during the early exercises and an accelerated return to overhead sports may jeopardize the stabilization and is permanently discussed in high-level overhead athletes.

Levine et al. [2] found adaptive changes in shoulder laxity in response to overhead throwing in young baseball players. Dominant shoulder of the baseball players older than 12 years developed significantly more inferior and anterior laxity than the group younger than 12 years [2]; so that overhead sports could be seen as a risk factor for developing a hyperlaxity and instability. Incidence of spontaneous recovery in MDI patients that discontinued overhead sports was found to be 8,7 times greater than in the group that continued to play overhead sports [3].

Young overhead athletes with symptomatic MDI showed a relative poor response to nonsurgical treatment, because many of these patients were seen to be not compliant with the in recommended long-term physiotherapy program over the long time of 6 months [6, 7]. These young athletes continued to suffer pain, and instability; lifestyle and sports adjustments were required to minimize symptoms [7]. Therefore, the indication for surgical treatment was more frequent in the group of MDI patients, active in overhead sports [3].

Following the described principles of surgery and rehabilitation, the majority of young overhead athletes with MDI showed "good" and "excellent" results after arthroscopic stabilization $[4,21]$. 95-97\% returned to their sports, $20 \%$ to a reduced level $[4,21]$. In our study the return to previous sports and levels was comparable with results reported after an open surgery [14] but lower than described by other authors after an arthroscopic treatment [4, 21]. This may be caused by our close patient-selection. We evaluated a risk group of MDI patients (Gerber B5) - highly active young athletes - after a failed conservative treatment.

Strengths of the present study were a clearly defined and accurate diagnosed, rare series of young overhead athletes 
with a persistent symptomatic MDI requiring surgical treatment and the uniform patient group. The complete follow-up was achieved in $90 \%$. All patients were diagnosed and treated by the senior author and followed up by the independent first author to keep highest continuousness.

However, this study has several limitations. First, the investigation was prospective, but randomisation or investigator masking was not performed. The number of patients was small, because our study focused on a defined subgroup of MDI-patients: young overhead athletes with an indication to surgical treatment. Follow-up was relatively short with median 39 months (range, 9-45 months). A continued long-term follow-up of our patients will be performed to detect the potential increasing long-term failure rate [14].

\section{CONCLUSION}

Young overhead athletes with a symptomatic true MDI with hyperlaxity (Gerber B5) and a persistent discomfort after an adequate exercise program represent a small, and still challenging patient group. The described arthroscopic technique stabilizes the glenohumeral joint effectively for everyday sportive activities. A return to overhead sports is possible but often at a reduced level. Patient's sportive expectations and claims have to be discussed before surgery.

\section{Trial Registration}

Reference number: 08042009/La (Hannover Medical School).

\section{CONFLICT OF INTEREST}

There is no conflict of interest.

\section{ABBREVIATIONS}

$$
\begin{array}{ll}
\mathrm{aC} & =\text { Anterior Capsule } \\
\mathrm{aCP} & =\text { Anterior Capsular Plication } \\
\mathrm{ADL} & =\text { Activities of Daily Living } \\
\text { a.p. } & =\text { Anterior - posterior } \\
\mathrm{CMS} & =\text { Constant Murley Score } \\
\mathrm{f} & =\text { Female } \\
\mathrm{G} & =\text { Glenoid } \\
\mathrm{H} & =\text { Humerus } \\
\mathrm{IC} & =\text { Interval Closure } \\
\mathrm{IGHL} & =\text { Inferior Glenohumeral Ligament } \\
\mathrm{m} & =\text { Male } \\
\mathrm{max} . & =\text { Maximum } \\
\mathrm{LBT} & =\text { Long Bicipital Tendon } \\
\mathrm{MDI} & =\text { Multidirectional Instability } \\
\mathrm{MGHL} & =\text { Medial Glenohumeral Ligament } \\
\mathrm{MRI} & =\text { Magnetic Resonance Imaging } \\
\mathrm{pCP} & =\text { Posterior Capsular Plication } \\
\mathrm{ROM} & =\text { Range of Motion } \\
\mathrm{SD} & =\text { Standard Deviation }
\end{array}
$$

[12] Neer CS II, Foster CR. Inferior capsular shift for involuntary inferior and multidirectional instability of the shoulder. A preliminary report. J Bone Joint Surg Am 1980; 62: 897-908.

[13] Burkhead WZ, Rockwood Jr CA. Treatment of instability of the shoulder with an exercise program. J Bone Joint Surg Am 1992; 74(6): 890-6.

[14] Pollock RG, Owens JM, Flatow EL, Bigliani LU. Operative results of the inferior capsular shift procedure for multidirectional instability of the shoulder. J Bone Joint Surg Am 2000; 82-A(7): 919-28.

[15] Hawkins RJ, Bokor DJ. Clinical evaluation of shoulder problems. In: Rockwood CA, Matsen FA III, Eds. The shoulder. Vol. 1. Philadelphia, USA: Saunders 1998; pp. 149-77.

[16] Altcheck DW, Warren RF, Skyhar MJ, Ortiz G. T-plasty modification of the Bankart procedure for multidirectional instability of the anterior and inferior types. J Bone Joint Surg Am 1991; 73(1): 105-12.

[17] Lippit SB, Harryman II DT, Matsen III FA. A practical tool for evaluation function: The simple shoulder test. In: Matsen III FA, Fu FHR, Hawkins RJ, Eds. The shoulder: A balance of Mobility and Stability. Rosemont: I.L. Am Acad Orthop Surg 1993; pp. 50118 .

[18] Constant CR, Murley AHG. A clinical method of functional assessment of the shoulder. Clin Orthop 1987; 214: 160-4.

[19] Rowe CR, Patel D, Southmayd WW. The Bankart procedure: a long term end-result study. J Bone Joint Surg Am 1978; 60: 1-16.

[20] Maurer H, Resch H. Schultergelenk. In: Kremer K, Lierse W, Platzer W, Schneider HW, Weller S, Eds. Chirurgische Operationslehre. Spezielle Anatomie, Indikationen, Technik, Komplikationen. Vol. 9: Schultergürtel, obere Extremität. Thieme Stuttgart-New York 1999; pp. 61-82.

[21] McIntyre LF, Caspari RB, Savoie III FH. The arthroscopic treatment of multidirectional shoulder instability: Two-year results of a multiple suture technique. Arthroscopy 1997; 13(4): 418-25.

[22] Cohen SB, Wiley W, Goradia VK, Pearson S, Miller MD. Anterior capsulorrhaphy: An in vitro comparison of volume reduction- 
arthroscopic plication versus open capsular shift. Arthroscopy 2005; 21(6): 659-64.

[23] Sekiya JK, Willobee JA, Miller MD, Hickman AJ, Willobee A. Arthroscopic multi-pleated capsular plication compared with open inferior capsular shift for reduction of shoulder volume in a cadaveric model. Arthroscopy 2007; 23(11): 1145-51.

[24] Mologne TS, Zhao K, Hongo M, Romeo AA, An KN, Provencher MT. The addition of rotator interval closure after arthroscopic repair of either anterior or posterior shoulder instability: Effect on glenohumeral translation and range of motion. Am J Sports Med 2008; 36(6): 1123-31.

[25] Shafer BL, Mihata T, McGarry MH, Tibone JE, Lee TQ. Effects of capsular plication and rotator interval closure in simulated multidirectional shoulder instability. J Bone Joint Surg Am 2008; 90(1): 136-44.
[26] Harryman DT, Sidles JA, Harris LS, Matsen III FA. The role of the rotator interval capsule in passive motion an stability of the shoulder. J Bone Joint Surg Am 1992; 74: 54-66.

[27] Gartsman GM, Roddey TS, Hammerman SM. Arthroscopic treatment of multidirectional glenohumeral instability: 2- to 5-year follow-up. Arthroscopy 2001: 17(3): 236-43.

[28] Treacy SH, Field LD, Savoie FH. Rotator interval capsule closure: an arthroscopic technique. Arthroscopy 1997: 13: 103-06.

[29] D'Alessandro DF, Bradley JP, Fleischli JE, Connor PM. Prospective evaluation of thermal capsulorrhaphy for shoulder instability: indications and results, two- to five-year follow-up. Am J Sports Med 2004; 32(1): 21-33.

[30] Wolf EM, Eakin CL. Arthroscopic capsular plication for posterior shoulder instability. Arthroscopy 1998; 14: 153-63.

(C) Voigt et al.; Licensee Bentham Open.

This is an open access article licensed under the terms of the Creative Commons Attribution Non-Commercial License (http://creativecommons.org/licenses/by-nc/ $3.0 /$ ) which permits unrestricted, non-commercial use, distribution and reproduction in any medium, provided the work is properly cited. 